\title{
Caracterização das atividades econômicas tradicionais no entorno das marismas no estuário da Lagoa dos Patos (RS)
}

\section{Characterization of the Traditional Activities on Salt Marshes at Patos Lagoon Estuary (RS)}

\author{
Juliano César MARANGONI* \\ César Serra Bonifácio COSTA**
}

\begin{abstract}
RESUMO
As marismas são ecossistemas entremarés predominantes na costa brasileira em latitudes maiores que $29^{\circ} \mathrm{S}$. No estuário da Lagoa dos Patos (RS), 6.837 ha de margens e ilhas são recobertos por marismas que vêm sendo utilizadas pela atividade agrícola e pecuária extensiva desde o século XVII. Este estudo visou caracterizar os usos das marismas pelas atividades econômicas tradicionais (agricultura e pecuária extensiva) desenvolvidas no estuário da Lagoa dos Patos. O trabalho foi efetuado nos municípios de Rio Grande e São José do Norte por meio de entrevistas semiestruturadas com pessoas envolvidas com a pecuária, a agricultura e a área urbana vivendo no entorno das marismas. As propriedades rurais com pecuária possuem uma área média de 306 ha, com uma lotação de 1 animal.ha ${ }^{-1}$. O pastejo por bovinos ocorre sobre Spartina densiflora (inverno) e Scirpus olneyi (verão), podendo consumir 4,6\% e 15,3\% da produção de biomassa anual, respectivamente. As propriedades agrícolas são de pequeno porte (área média de 19 ha, com 4,2 ha cultivados), produzindo principalmente cebola e hortigranjeiros. Os agricultores utilizam 6,4\% da biomassa anual de $S$. densiflora e 20,5\% de Juncus kraussii como cobertura vegetal, adubação e construção de pequenos galpões. A maioria dos agricultores e pecuaristas relatou a expansão nos últimos 50 anos de $J$. kraussii sobre campos, áreas cultivadas e marismas recobertas por S. densiflora, bem como os moradores urbanos observaram a erosão das margens no mesmo período. As técnicas agropecuárias tradicionalmente utilizadas nas últimas décadas na região estuarina da Lagoa dos Patos permitiram a reprodução social da atividade econômica conjuntamente com a conservação das marismas.
\end{abstract}

Palavras-chave: marismas; pecuária; agricultura.

\begin{abstract}
Salt marshes are predominant intertidal coastal ecosystem in $29^{\circ} \mathrm{S}$ and higher latitudes. At Patos Lagoon estuary (RS), 6.837 ha of salt marshes occupy margins and islands that have been used by farming and

\footnotetext{
• Oceanógrafo. Laboratório de Ecologia Vegetal Costeira. Instituto de Oceanografia. Universidade Federal do Rio Grande (FURG). Email: julianomarangoni@ pop.com.br

** Oceanógrafo. Laboratório de Biotecnologia de Halófitas. Instituto de Oceanografia. Universidade Federal do Rio Grande (FURG). Email: docosta@furg.br
} 
ranching since XVII century. This study aimed to characterize the use of salt marshes by economical activities (farming and ranching) at Patos Lagoon estuary. This study was carried out in the counties of Rio Grande and São José do Norte throughout semi-structured interviews with representative of farmers, ranchers and urban residents living nearby salt marshes. Neighboring ranches have an average area of 306 ha with a stocking density of 1 animal.ha ${ }^{-1}$. Cattle graze Spartina densiflora (during winter) and Scirpus olneyi (during summer), and animals can eat $4.6 \%$ to $15.3 \%$ of plant biomass production, respectively. Neighboring farms have small areas (average of 19.3 ha with 4.2 ha planted) and onion and vegetables are the main crops. Farmers utilize $6.4 \%$ of annual biomass of S. densiflora and $20.5 \%$ of Juncus kraussii for ground cover, manuring and construction of small sheds. Most of farmers and ranchers described the expansion along the last 50 years of $J$. kraussii over grasslands, crop areas and $S$. densiflora salt marshes, and urban residents reported the erosion of estuarine margins during the same period. The farming and ranching techniques used in the last decades at Patos Lagoon estuary allowed the social reproduction of economical activity together with the conservation of salt marshes.

Key-words: salt marshes; ranching; farming.

\section{Introdução}

As marismas são ecossistemas costeiros entremarés vegetados por plantas herbáceas que suportam o alagamento periódico e a variação de salinidade, ocupando áreas abrigadas de estuários, baías e lagunas em regiões temperadas, subtropicais e tropicais (ADAM, 1990; COSTA; DAVY, 1992). Caracterizam-se pela produção de elevadas quantidades de matéria orgânica (GAONA et al., 1996; PEIXOTO; COSTA, 2004; CUNHA et al., 2005), sendo sua biomassa um importante item alimentar de detritívoros estuarinos (D’INCAO et al., 1990; ABREU et al., 2006).

$\mathrm{Na}$ costa brasileira, as marismas são predominantes nas regiões costeiras ao sul da latitude $29^{\circ} \mathrm{S}$ (Laguna-SC), ocupando 7.375 ha da costa do Rio Grande do Sul, vegetando principalmente às margens e ilhas do estuário da Lagoa dos Patos (RS) (6.837 ha - 92,7\% da área total) (COSTA; DAVY 1992; COIMBRA; COSTA 2006).

Pelo menos $10 \%$ da área total das marismas na região estuarina da Lagoa dos Patos foi convertida pela expansão urbana, portuária e industrial entre o século XIX e meados do século XX (SEELIGER; COSTA, 1998; MARANGONI; COSTA, 2009a). A importância ambiental das marismas levou ao enquadramento destes ambientes como áreas de preservação permanente, tanto no Código Florestal de 1965 (Lei Federal n. ${ }^{\circ}$ 4.771), como na Lei de Regulamentação de Ocupação dos Espaços Naturais de 1986 (Lei Municipal n. ${ }^{\circ}$ 4.116). Apesar de, em menor escala, nas últimas cinco décadas do século XX continuarem ocorrendo perdas de áreas de marismas por atividade antrópica - como a expansão urbana e o desenvolvimento da aquicultura -, processos erosivos naturais passaram a ter uma maior importância relativa nestas perdas (MARANGONI; COSTA, 2009a). Maiores vazões dos tributários da bacia de drenagem Patos-Mirim, associadas a um aumento de precipitação na região, à intensificação dos ventos dominantes e à elevação do nível médio relativo do mar são os mais prováveis fatores causais do processo erosivo em andamento (MARENGO, 2006; COSTA et al., 2009; MARANGONI; COSTA, 2009a).

Estas marismas também vêm sendo utilizadas por atividades econômicas tradicionais, como a agricultura e a pecuária (FREIRE, 2003; MANZONI, 2005; MARANGONI; COSTA, 2009b; COSTA et al., 2009); contudo, não há evidências da supressão deste ambiente por estas atividades, pelo menos nos últimos 50 anos (MARANGONI; COSTA, 2009a). As formas de uso das marismas por estas comunidades locais são oriundas provavelmente de técnicas introduzidas a partir do século XVIII pelos colonizadores. Uma vez que a produção material por comunidades tradicionais é dependente da preservação dos ambientes em que vivem, elas desenvolvem formas adequadas de manejo dos recursos naturais (DIEGUES, 2001). Consequentemente, importantes lições de conservação podem ser aprendidas do estudo da interação entre comunidades tradicionais e as marismas. Para que ocorra a reprodução das atividades tradicionais locais, conjuntamente com a persistência das marismas, possivelmente deve existir uma adequação da produção econômica com a capacidade de resposta deste ecossistema. Este estudo visou caracterizar os usos das marismas pelas atividades agrícolas e pecuárias desenvolvidas no estuário da Lagoa dos Patos por meio de entrevistas com os atores envolvidos, bem como avaliar a compatibilidade destas atividades com a produtividade e a estrutura da comunidade vegetal deste ecossistema. 


\section{Métodos}

\section{Área de estudo}

Este estudo foi realizado no entorno das 24 unidades de marisma do estuário da Lagoa dos Patos, espacialmente distintas por descontinuidade física ou cobertura vegetal (COSTA et al., 1997; NOGUEIRA; COSTA, 2003), englobando os municípios costeiros de Rio Grande (RG) e São José do Norte (SJN) $\left(31^{\circ} 50^{\prime}-32^{\circ} 09^{\prime} \mathrm{S} ; 52^{\circ} 00^{\prime}-52^{\circ} 15^{\prime} \mathrm{W}\right)$ (Figura 1).

\section{Entrevistas}

O presente trabalho é exploratório descritivo, tendo sido efetuado por meio de entrevistas semiestruturadas com indivíduos pertencentes a grupos de pessoas com atividade econômica diretamente associada às marismas e/ou que vivem em suas adjacências. Desta forma, foram entrevistadas pessoas relacionadas principalmente com a pecuária e a agricultura (proprietários, arrendatários, administradores), além de moradores urbanos.

As entrevistas foram efetuadas entre abril/2006 e maio/2008, sendo realizadas de maneira intencional, com

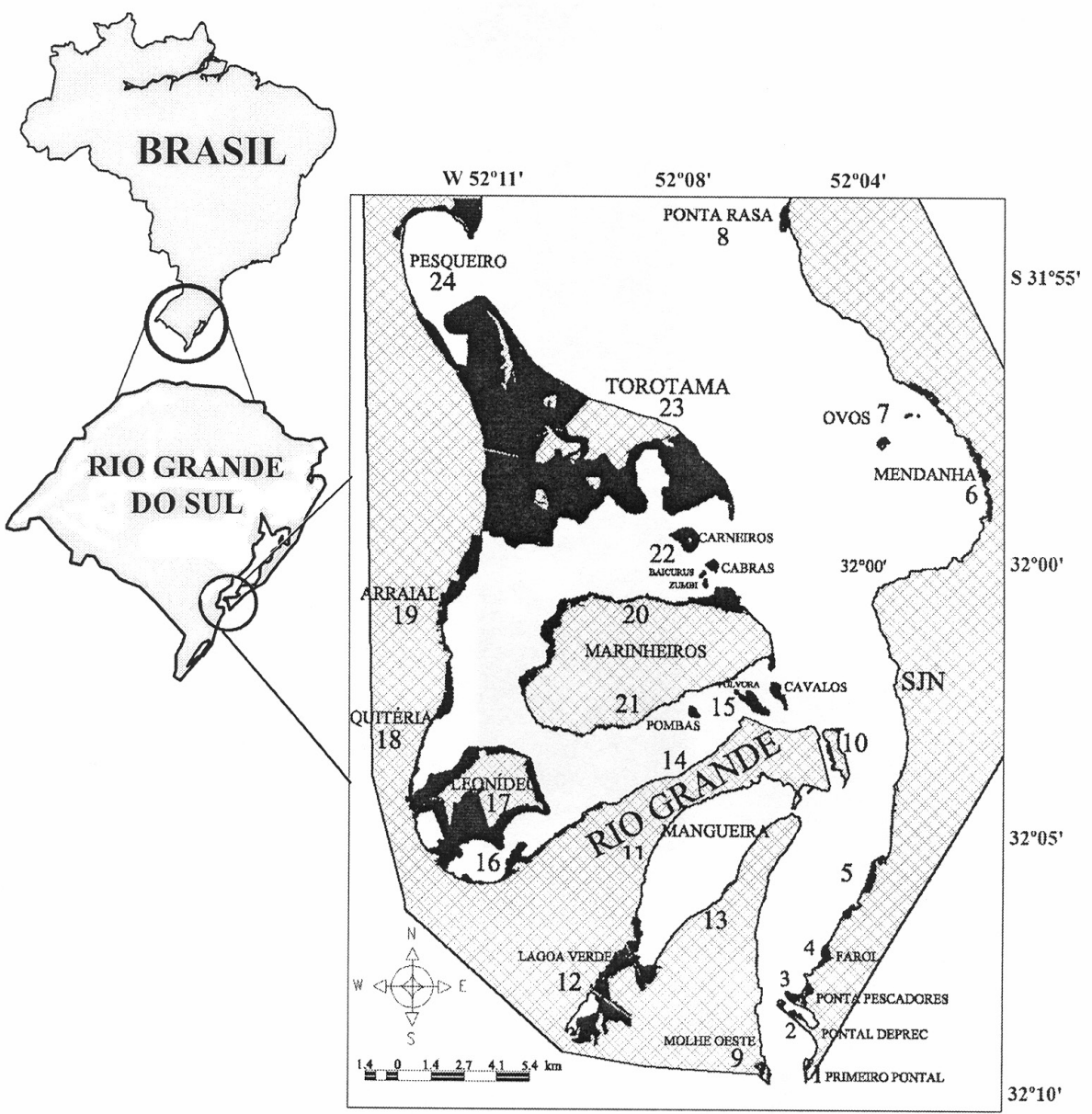

FIGURA 1 - ESTUÁRIO DA LAGOA DOS PATOS (RS, BRASIL) COM A LOCALIZAÇ̃̃O DAS 24 UNIDADES DE MARISMAS (ÁREAS ESCURAS) NOS MUNICÍPIOS DE RIO GRANDE (RG) E SÃO JOSÉ DO NORTE (SJN). 
indivíduos vivendo no local preferencialmente por mais de 20 anos. A amostragem foi realizada utilizando o método Bola de Neve (snowball ou chain referral sampling) (BERG, 2006). Este método de amostragem é baseado em uma série de indicações feitas dentro de um círculo/grupo de pessoas. A amostragem é procedida a partir da seleção aleatória de um indivíduo de um grupo-alvo de interesse (p. ex. agricultores) que posteriormente indica (identifica) outros indivíduos que pertençam ao mesmo grupo-alvo.

$O$ roteiro de entrevista possuía cinco partes principais: (i) informações sobre a atividade econômica; (ii) uso das marismas (atual e passado); (iii) observação de mudanças ambientais nas marismas; (iv) conhecimento de algumas funções ecológicas das marismas; e (v) conhecimento sobre legislação ambiental.

O trabalho de campo foi realizado por intermédio da abordagem de um morador qualquer na unidade de marisma a fim de localizar as pessoas com maior tempo de vivência no local. Uma vez localizada esta pessoa fonte, a entrevista demorava de 30 minutos até 1 hora, sendo todas as respostas anotadas pelo entrevistador. As informações oriundas das entrevistas foram categorizadas em função da atividade econômica diretamente relacionada com as marismas e/ ou em suas adjacências (categorias: Pecuária, Agricultura e Morador Urbano).

\section{Resultados}

Em algumas marismas de SJN (Primeiro Pontal, Pontal Deprec, Ilha dos Ovos) e RG (Ilha do Terrapleno, Ilha das Pombas, Pólvora, Cavalos, Carneiros, Cabras, Baicurus e Zumbi) não foi possível realizar entrevistas devido à inexistência de atividade econômica ou moradores no entorno. Nas 13 unidades de marisma onde existiam ocupações humanas em seu entorno foram realizadas 58 entrevistas. Estas abrangeram 10 representantes da pecuária, 37 da agricultura e 11 da área urbana, com um período médio de vivência no local de 48 anos (pecuária - 38 anos; agricultura - 52 anos; urbano - 53 anos) (Tabelas 1 e 2). O número de entrevistas para cada atividade foi compatível com a distribuição dos estabelecimentos rurais no município de Rio Grande e São José do Norte (IBGE, 2006 - Censo Agropecuário).

\section{Pecuária}

A criação de gado é apontada como principal atividade econômica pelos entrevistados no entorno das marismas no Saco do Mendanha em SJN e Lagoa Verde, Mangueira Sul, Arraial, Torotama e Pesqueiro em RG (Figura 1; Tabela 1). As propriedades rurais possuem uma área média de 306 ha, onde são criados animais com o uso do sistema extensivo, com uma lotação média de 1 animal. $\mathrm{ha}^{-1}$. A pecuária utiliza as marismas como pastagem, quando vegetadas principalmente por macega (Spartina densiflora) e/ou junça A (Scirpus olneyi). Além disso, houve o relato da utilização, no passado, da macega como matéria-prima para cobertura de casas e galpões (Tabela 3). Dentre as mudanças ambientais observadas nas marismas, 50\% dos entrevistados deste grupo destacou a expansão do junco (Juncus kraussii) sobre os campos e marismas de macega nos últimos 30 anos, principalmente nas localidades do Arraial e Torotama, em RG (Tabela 3). A maioria dos entrevistados (80\%) declarou que não existia ou não sabiam da existência de relação entre as marismas e a fauna estuarina (peixes e camarão). Em contrapartida, $80 \%$ das pessoas acreditam que as marismas protegem as margens contra a erosão. Quase todos os entrevistados desconhecem as leis que incidem sobre as marismas; entretanto, metade dos entrevistados comentou que não pode ser ateado fogo e nem remover as marismas (Tabela 3 ).

\section{Agricultura}

A agricultura é a atividade econômica principal no entorno das marismas de SJN, na Ponta dos Pescadores, Farol, Sul de SJN, Saco do Mendanha e Ponta Rasa, e em RG nas marismas do Justino, Leonídeo, Quitéria, Arraial e Ilha dos Marinheiros (Figura 1; Tabela 1). As propriedades rurais se caracterizam pelo pequeno porte (área média de 19,3 ha), sendo a área cultivada em média de apenas 4,2 ha (Tabela 2), produzindo principalmente cebola e hortigranjeiros. Uma característica peculiar da maioria dos agricultores é a pequena criação de animais associada à atividade agrícola; $54 \%$ dos entrevistados criavam gado (leite e corte) e cavalos, com uma lotação média de 1 animal.ha ${ }^{-1}$. A atividade 


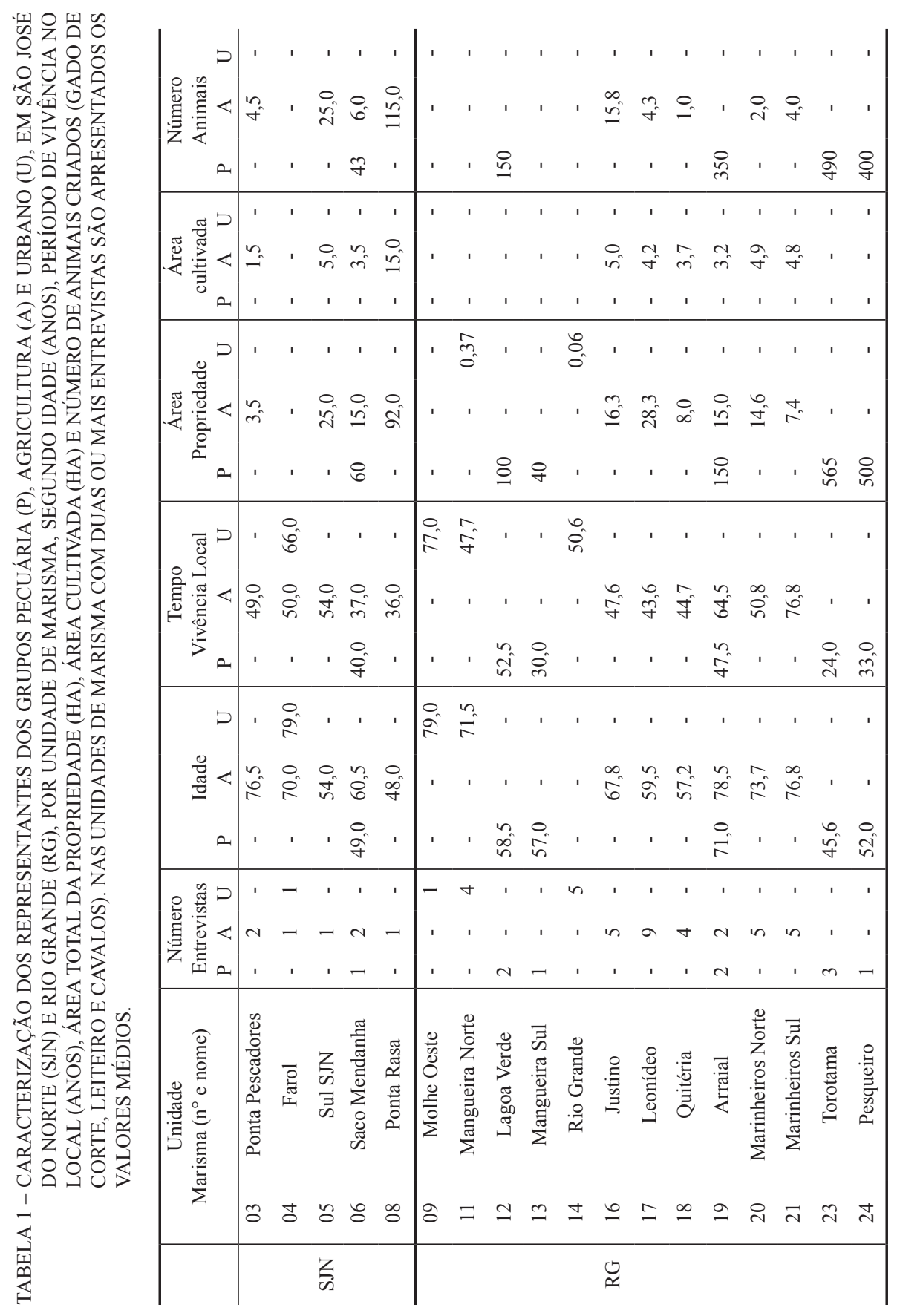


TABELA 2 - CARACTERIZAÇÃO GERAL DOS REPRESENTANTES DOS GRUPOS PESQUISADOS (PECUÁRIA, AGRICULTURA E URBANO). SÃO APRESENTADOS OS VALORES MÉDIOS (ENTRE PARÊNTESES MÍNIMOS E MÁXIMOS) DA IDADE (ANOS), PERÍODO DE VIVÊNCIA NO LOCAL - PVL (ANOS), ÁREA TOTAL DA PROPRIEDADE - AT (HA), ÁREA CULTIVADA - AC (HA) E NÚMERO DE ANIMAIS CRIADOS.

\begin{tabular}{|c|c|c|c|c|c|c|}
\hline & $\begin{array}{l}\text { Número de } \\
\text { Entrevistas }\end{array}$ & $\begin{array}{l}\text { Idade } \\
\text { (anos) }\end{array}$ & $\begin{array}{c}\text { PVL } \\
\text { (anos) }\end{array}$ & $\begin{array}{l}\text { AT } \\
\text { (ha) }\end{array}$ & $\begin{array}{l}\text { AC } \\
\text { (ha) }\end{array}$ & $\begin{array}{l}\text { Número } \\
\text { Animais }\end{array}$ \\
\hline Pecuária & 10 & $\begin{array}{c}55,4 \\
(34-73)\end{array}$ & $\begin{array}{c}37,5 \\
(5-73)\end{array}$ & $\begin{array}{c}306,5 \\
(60-1000)\end{array}$ & ----- & $\begin{array}{c}320 \\
(42-800)\end{array}$ \\
\hline Agricultura & 37 & $\begin{array}{c}66,3 \\
(37-85)\end{array}$ & $\begin{array}{c}51,6 \\
(10-85)\end{array}$ & $\begin{array}{c}19,3 \\
(2-135)\end{array}$ & $\begin{array}{c}4,2 \\
(1-15)\end{array}$ & $\begin{array}{c}14,4 \\
(1-142)\end{array}$ \\
\hline Urbano & 11 & $\begin{array}{c}70,5 \\
(53-81)\end{array}$ & $\begin{array}{c}53,4 \\
(28-77)\end{array}$ & $\begin{array}{c}0,2 \\
(0,02-0,72)\end{array}$ & ----- & ----- \\
\hline
\end{tabular}

TABELA 3 - RESPOSTAS DOS REPRESENTANTES DO GRUPO DA PECUÁRIA(N = 10) SOBRE OS TIPOS DE PLANTAS DE MARISMA EM SUA PROPRIEDADE, O SEU USO ATUAL E PASSADO, A ÉPOCA DE PASTAGEM, AS MUDANÇAS AMBIENTAIS OBSERVADAS, O MANEJO REALIZADO DAS MARISMAS, A RELAÇÃO ENTRE A MARISMA E A FAUNA ESTUARINA (CAMARÃO E PEIXE), A RELAÇÃO ENTRE A MARISMA E A EROSÃO DAS MARGENS E O CONHECIMENTO DA LEGISLAÇÃO SOBRE A MARISMA.

\begin{tabular}{c|l}
\hline Plantas & $\begin{array}{l}\text { Macega (Spartina densiflora), Junça A (Scirpus olneyi), Junco (Juncus kraussii), } \\
\text { Macega Mole (Spartina alterniflora) }\end{array}$ \\
\hline Uso Atual & Pastagem extensiva - Macega e Junça A \\
\hline Uso Passado & $\begin{array}{l}\text { Pastagem extensiva - Macega e Junça A } \\
\text { Cobertura de Casa e Galpão - Macega }\end{array}$ \\
\hline Época da Pastagem & $\begin{array}{l}\text { Campo - ano todo } \\
\text { Macega - inverno } \\
\text { Junça A - primavera e verão }\end{array}$ \\
\hline Mudanças Ambientais & $\begin{array}{l}\text { Unidade 06 - Expansão de Juncus acutus nos últimos } 10 \text { anos e diminuição do Campo; } \\
\text { Unidade 19 - Expansão do Junco nos últimos 30 anos e diminuição/extinço da }\end{array}$ \\
& $\begin{array}{l}\text { Macega; } \\
\text { Unidade 23 - Expansão do Junco nos últimos 20 anos, expansão da Macega e } \\
\text { diminuição Campo; } \\
\text { Unidade 24 - Expansão do Junco nos últimos } 10 \text { anos, expansão do Campo e } \\
\text { diminuição Macega; }\end{array}$ \\
\hline Fauna Estuarina & $\begin{array}{l}\text { Tem relação - 20\% } \\
\text { Não tem relação - 50\% } \\
\text { Não sabe - 30\% }\end{array}$ \\
\hline Erosão das Margens & $\begin{array}{l}\text { Proteção das Margens - } 80 \% \\
\text { Não tem relação - 20\% }\end{array}$ \\
\hline Legislação & $\begin{array}{l}\text { Não pode por Fogo - 40\% } \\
\text { Não pode ser Removida - 10\% } \\
\text { Não sabe - 50\% }\end{array}$ \\
\hline
\end{tabular}


agrícola de pequeno porte no entorno do estuário se caracteriza pela diversidade na produção, levando desta maneira à multiplicidade de uso das marismas. $\mathrm{O}$ uso mais difundido de plantas de marisma é a incorporação direta de macega e junco nos canteiros de cultivo como cobertura vegetal e, eventualmente, para construção/cobertura de pequenos galpões (Figura 2). Segundo os entrevistados, são utilizados 316 feixes de macega (pesando $\sim 5 \mathrm{~kg}$ cada feixe, medida comumente utilizada pelos agricultores), perfazendo aproximadamente $1.580 \mathrm{~kg} \cdot \mathrm{ha}^{-1}$. ano ${ }^{-1}$ e $6.800 \mathrm{~kg} \cdot \mathrm{ha}^{-1}$. ano ${ }^{-1}$ de junco para os usos mais comuns (área média cortada de $2.000 \mathrm{~m}^{2}$ ), sendo que para a cobertura/construção de galpões faz-se necessário de 1.000 a 2.000 feixes (de 5.000 a $10.000 \mathrm{~kg}$ ) (Tabela 4). De acordo com alguns agricultores, o corte da vegetação ocorre através de um processo de rotação, isto é, a colheita das plantas de marisma é efetuada de maneira alternada dentro da propriedade, permitindo desta forma a recuperação da cobertura vegetal e a contínua disponibilidade de matéria-prima. Dentre os agricultores entrevistados, 97\% relataram sua percepção de que ocorreram mudanças ambientais nas marismas, sendo que a maioria (61\%) destacou a expansão do junco ( $J$. kraussii) nos últimos 50 anos, nas marismas da Ponta dos Pescadores (SJN), Justino, Leonídeo, Quitéria e Arraial (RG), bem como um aumento da junça B (Scirpus maritimus) (17\%) sobre as áreas de macega na Ilha dos Marinheiros (RG) (Tabela 4). A maioria dos agricultores (86\%) declarou que não há ou não sabe da interação entre as marismas e a fauna estuarina, mas $92 \%$ conferiram às marismas o importante papel de proteção contra os processos erosivos. A maior parte dos agricultores não sabe da existência de leis que incidem sobre as marismas (65\%), sendo que apenas 35\% relataram a necessidade de preservação e a proibição de atear fogo nas marismas (Tabela 4).

\section{Morador urbano}

Dentre os grupos estudados, os moradores urbanos vivem no entorno das marismas no Farol em SJN e nas localidades de Molhe Oeste e Saco da Mangueira, em RG, bem como na própria cidade de Rio Grande (Figura 1; Tabela 1). Os entrevistados da zona urbana relataram o pastejo por cavalos como a única forma de uso das marismas. $\mathrm{O}$ pastejo ocorre principalmente sobre a macega mole e junça B, encontradas em apenas 18\% das propriedades visitadas (Tabela 5). A erosão das margens foi a principal mudança ambiental reportada pelos entrevistados, com uma taxa de erosão da margem de 1,66 m.ano ${ }^{-1}$ no Farol (SJN) e uma taxa média de 0,66 m.ano ${ }^{-1}$ em RG (Mangueira e Rio Grande) (Tabela 5). Dentre os entrevistados, $64 \%$ acreditavam não existir relação das marismas com os peixes e o camarão. Adicionalmente, a maioria (82\%) declarou que as marismas atenuavam a ação das ondas, minimizando o processo erosivo nas margens. A maior parte desconhece as leis sobre marismas, sendo que $18 \%$ dos entrevistados tinham conhecimento da proibição de atear contra fogo, corte da vegetação e realização de aterros (Tabela 5).

\section{Discussão}

As atividades econômicas tradicionais que predominam no entorno das marismas do estuário da Lagoa dos Patos são baseadas na pecuária extensiva e na pequena atividade agrícola. Este perfil é semelhante ao observado em toda zona rural de ambos os municípios costeiros que formam o estuário, composta predominantemente por propriedades com até 200 ha ( $89 \%$ das propriedades em RG e $98 \%$ em SJN), produzindo principalmente cebola, gado, hortigranjeiros e arroz (IBGE, 1996 - Censo Agropecuário). A atividade agropecuária responde por aproximadamente $2,6 \%$ do produto interno bruto de $\mathrm{RG}$ e $32,3 \%$ de $\mathrm{SJN}$, sendo responsável por empregar aproximadamente 4.140 pessoas em RG (2\% da população total) e 6.200 em SJN (24,9\% da população total) (IBGE, 2006 - Censo Agropecuário e IBGE, 2007 - Contagem da População). O valor médio do tamanho das propriedades no entorno das marismas dedicadas principalmente à criação de animais (306 ha) foi aproximadamente 4 vezes maior do que a média dos municípios de RG e SJN, de 73,4 ha, encontrada pelo Censo Agropecuário 2006. Já os valores de lotação de animais foram semelhantes entre o entorno da marisma (1 animal. ha $^{-1}$ ) e zona rural de RG (1) e SJN (0,93) (IBGE, 2006 Censo Agropecuário).

O pastejo pelos bovinos ocorre com maior intensidade sobre as plantas de marisma, principalmente $S$. densiflora (macega), durante os meses de inverno devido à diminuição da produção de biomassa vegetal dos campos nativos, áreas preferenciais de pastagem. Segundo um entrevistado, "a macega é a vida para o gado durante o inverno". Nesta época do ano, as baixas temperaturas e alagamento limitam a disponibilidade de pasto, respectivamente, nos campos altos e nos campos baixos. O pastejo sobre junça $\mathrm{A}$ 
MARANGONI, J. C.; COSTA, C. S. B. Caracterização das atividades econômicas tradicionais...

TABELA 4 - RESPOSTAS DOS REPRESENTANTES DO GRUPO DA AGRICULTURA (N = 37) SOBRE OS TIPOS DE PLANTAS DE MARISMA EM SUA PROPRIEDADE, AS PLANTAS CULTIVADAS, O SEU USO ATUAL E PASSADO, A QUANTIDADE UTILIZADA, A ÉPOCA UTILIZADA, AS MUDANÇAS AMBIENTAIS OBSERVADAS, O MANEJO REALIZADO DAS MARISMAS, A RELAÇÃO ENTRE A MARISMA E A FAUNA ESTUARINA (CAMARÃO E PEIXE), A RELAÇÃO ENTRE A MARISMA E A EROSÃO DAS MARGENS E O CONHECIMENTO DA LEGISLAÇÃO SOBRE A MARISMA.

\begin{tabular}{|c|c|}
\hline Plantas & $\begin{array}{l}\text { Macega (Spartina densiflora), Junco (Juncus kraussii), Junça A (Scirpus olneyi), Junça B (Scirpus } \\
\text { maritimus), Macega Mole (Spartina alterniflora), Capororóca (Myrsine parvifolia) }\end{array}$ \\
\hline Plantas Cultivadas & Cebola e hortigranjeiros \\
\hline Uso Atual & $\begin{array}{l}\text { Enterrar nos canteiros - Macega e Junco } \\
\text { Cobertura vegetal nos canteiros - Macega e Junco } \\
\text { Cama para os animais (gado, cavalo, porcos) para formação de esterco - Macega e Junco } \\
\text { Forragem - Macega } \\
\text { Pastagem - Macega, Junça A, Junça B e Junco (plântulas) } \\
\text { Cobertura de casa e galpão e construção de galpão - Macega }\end{array}$ \\
\hline Uso Passado & $\begin{array}{l}\text { Enterrar nos canteiros - Macega, Junco, Junça A e Macega Mole } \\
\text { Cobertura vegetal nos canteiros - Macega e Junco } \\
\text { Cama para os animais (gado, cavalo, porcos) para formação de esterco - Macega, Junco e Junça A } \\
\text { Forragem - Macega, Junça A e Macega Mole } \\
\text { Pastagem - Macega, Junça A e Junça B } \\
\text { Cobertura de casa e galpão e construção de galpão - Macega e Junco }\end{array}$ \\
\hline Mudanças Ambientais & $\begin{array}{l}\text { Unidade } 03 \text { - Expansão de Junco nos últimos } 20 \text { anos e diminuição Campo e Macega } \\
\text { Unidade } 08 \text { - Expansão do Campo nos últimos } 10 \text { anos e diminuição Macega } \\
\text { Unidade } 16 \text { - Expansão do Junco nos últimos 30-50 anos e diminuição/extinção Macega } \\
\text { Unidade } 17 \text { - Expansão do Junco nos últimos 15-40 anos e diminuição/extinção Campo e Macega } \\
\text { Unidade } 18 \text { - Expansão do Junco, diminuição/extinção Macega e diminuição Área Cultivada } \\
\text { Unidade } 19 \text { - Expansão do Junco, diminuição/extinção Macega e diminuição Área Cultivada } \\
\text { Unidade } 20 \text { - Aumento da Junça B e diminuição da Macega } \\
\text { Unidade } 21 \text { - Aumento da Junça B e diminuição da Macega }\end{array}$ \\
\hline Fauna Estuarina & $\begin{array}{l}\text { Tem relação }-28 \% \\
\text { Não tem relação }-58 \% \\
\text { Não sabe }-14 \%\end{array}$ \\
\hline Erosão das Margens & $\begin{array}{l}\text { Proteção das Margens - 92\% } \\
\text { Não tem relação }-8 \%\end{array}$ \\
\hline Legislação & $\begin{array}{l}\text { Não pode por Fogo }-27 \% \\
\text { Preservar }-5 \% \\
\text { Pode cortar para usar na propriedade }-3 \% \\
\text { Não Sabe }-65 \%\end{array}$ \\
\hline
\end{tabular}

(S. olneyi) é mais frequente durante a primavera e o verão, em função da disponibilidade de novas plantas (PEIXOTO, 1997). A pecuária extensiva no entorno das marismas se caracteriza por uma densidade média de 1 animal.ha $^{-1}$. O gado de corte geralmente consome matéria vegetal seca (peso seco $=$ PS) diária equivalente a $2-3 \%$ do peso vivo (CORDOVA et al., 1978; ALMEIDA, 2005; VERNEQUE, 2007; BARBOSA, 2007), fazendo com que um animal adulto $(500 \mathrm{~kg})$ ingira em média $12,5 \mathrm{~kg}$ PS.dia ${ }^{-1}$. Desta forma, um animal pastando exclusivamente $S$. densiflora, durante três meses do ano (inverno), consumiria $1.125 \mathrm{~kg}$ PS de biomassa aérea, aproximadamente $4,6 \%$ da quantidade produzida em um ano (produção estimada $=24.462$ kg PS.ha- ${ }^{-1}$; PEIXOTO; COSTA, 2004). O pastejo sobre $S$. olneyi, durante seis meses por ano (primavera/verão), pastaria $2.250 \mathrm{~kg}$ PS de plantas, consumindo $15,3 \%$ da biomassa aérea produzida anualmente (produção estimada $=14.745 \mathrm{~kg}$ PS.ha ${ }^{-1}$; PEIXOTO, 1997). O uso das marismas no estuário da Lagoa dos Patos como área de pastagem remonta possivelmente ao século XVII, quando da presença 

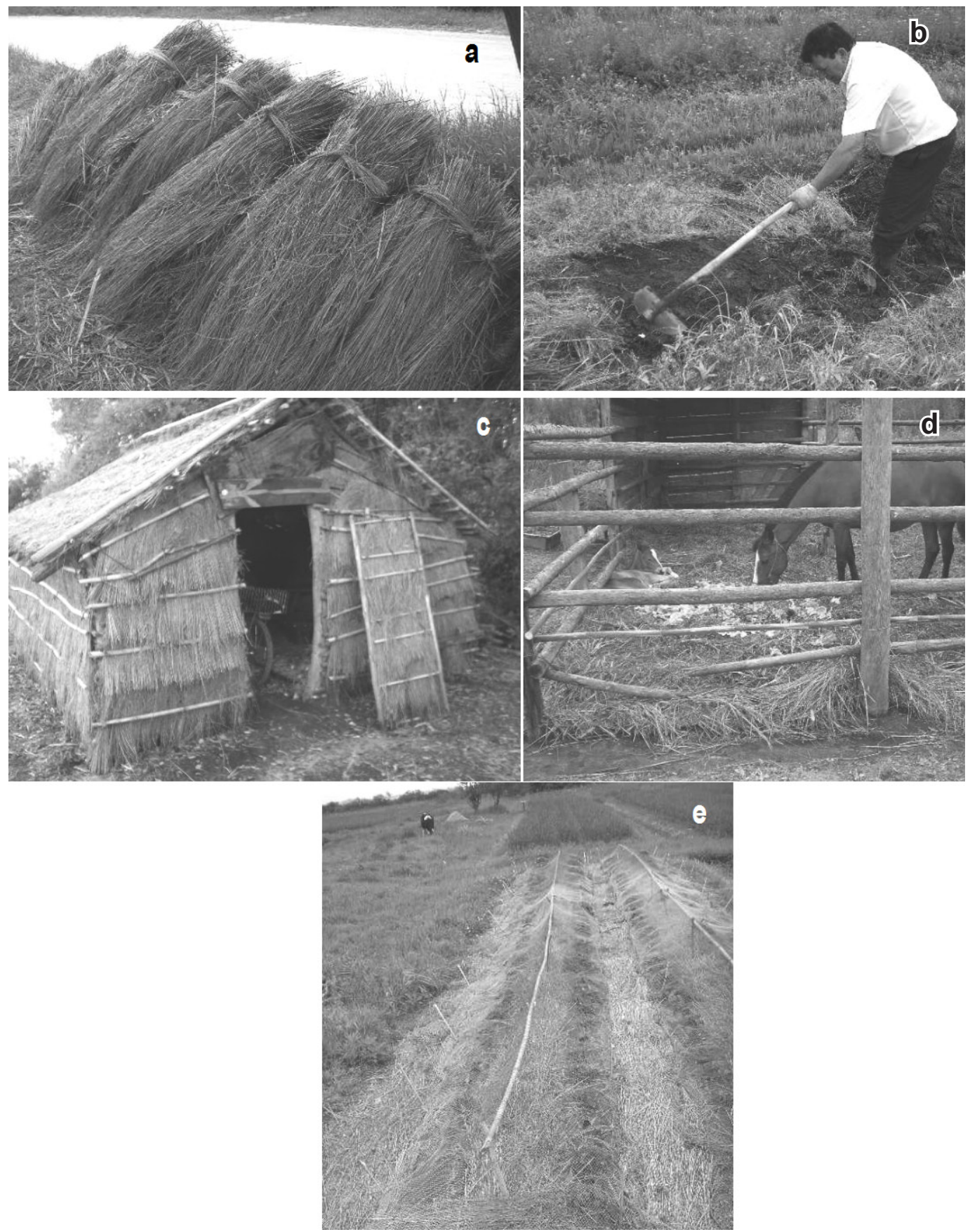

FIGURA 2 - MULTIPLICIDADE DE USO DA MACEGA (SPARTINA DENSIFLORA) PELOS AGRICULTORES, SENDO: $\mathrm{a}=$ FEIXE; $\mathrm{b}=$ UTILIZAÇÃO DIRETA NOS CANTEIROS; $\mathrm{c}=$ GALPÃO DE MACEGA; $\mathrm{d}=$ CAMA PARA OS ANIMAIS; e = COBERTURA VEGETAL. 
MARANGONI, J. C.; COSTA, C. S. B. Caracterização das atividades econômicas tradicionais...

TABELA 5 - RESPOSTAS DOS REPRESENTANTES DO GRUPO DE RESIDENTES URBANOS (N = 11) SOBRE OS TIPOS DE PLANTAS DE MARISMA EM SUA PROPRIEDADE, O SEU, USO ATUALE PASSADO, AS MUDANÇAS AMBIENTAIS OBSERVADAS, A RELAÇÃO ENTRE A MARISMA E A FAUNA ESTUARINA (CAMARÃO E PEIXE), A RELAÇÃO ENTRE A MARISMA E A EROSÃO DAS MARGENS E O CONHECIMENTO DA LEGISLAÇÃO SOBRE A MARISMA.

\begin{tabular}{|c|c|}
\hline Plantas & $\begin{array}{l}\text { Atualmente Macega Mole (Spartina alterniflora) e Junça B (S. maritimus) (18\% dos } \\
\text { entrevistados) } \\
\text { Antigamente Macega (Spartina densiflora) Macega Mole (Spartina alterniflora), Junça } \\
\text { A (Scirpus olneyi), Junça B (Scirpus maritimus), Junco (Juncus kraussii) (100\% dos } \\
\text { entrevistados) }\end{array}$ \\
\hline Uso Atual & Pastagem (Cavalos) - Macega Mole \\
\hline Uso Passado & $\begin{array}{l}\text { Enterrar nos canteiros - Macega, Junco e Macega Mole } \\
\text { Pastagem - Macega e Macega Mole } \\
\text { Cama para os animais - Macega }\end{array}$ \\
\hline Mudanças Ambientais & $\begin{array}{l}\text { Unidade } 04 \text { - Erosão Margem (perda de } 50 \mathrm{~m} \text { de margem em } 30 \text { anos; taxa estimada de } \\
1,66 \mathrm{~m} . \text { ano }^{-1} \text { ) } \\
\text { Unidade } 11 \text { - Erosão Margem (perda média de } 17 \mathrm{~m} \text { de margem em } 37 \text { anos; taxa estimada } \\
\text { de } 0,46 \mathrm{~m} \cdot \text { ano }^{-1} \text { ) } \\
\text { Unidade } 14 \text { - Erosão Margem (perda média de } 35 \mathrm{~m} \text { de margem em } 40 \text { anos; taxa estimada } \\
\text { de } 0,87 \mathrm{~m} \cdot \text { ano }^{-1} \text { ) }\end{array}$ \\
\hline Fauna Estuarina & $\begin{array}{l}\text { Tem relação }-36 \% \\
\text { Não tem relação }-64 \%\end{array}$ \\
\hline Erosão Margens & $\begin{array}{l}\text { Proteção das Margens - } 82 \% \\
\text { Não tem relação - } 18 \%\end{array}$ \\
\hline Leis & $\begin{array}{l}\text { Não pode por Fogo e nem Cortar }-9 \% \\
\text { Não pode Aterrar }-9 \% \\
\text { Não Sabe }-82 \%\end{array}$ \\
\hline
\end{tabular}

do gado selvagem oriundo dos redutos jesuíticos. A partir do século XVIII, com a fundação da cidade de Rio Grande (1737), ocorreu o estabelecimento de propriedades rurais dedicadas à atividade pecuária através da captura de gado selvagem para o comércio de couro e pela implantação de estâncias criadoras de gado. Na maior área de marismas da região (Ilha da Torotama; MARANGONI; COSTA, 2009a), foi criada a Estância Real da Torotama para abastecimento da povoação e dos militares (QUEIROZ, 1987; VIEIRA; RANGEL, 1993).

Possivelmente a agricultura vem usando as plantas das marismas desde o processo colonizador de Rio Grande (1737). As propriedades agrícolas no entorno das marismas possuem um tamanho médio (19,3 ha) semelhante à média de 13,7 ha das propriedades agrícolas dos municípios de RG e SJN pelo IBGE (2006 - Censo Agropecuário). Nestas pequenas propriedades, as plantas de marismas são utilizadas como matéria-prima para múltiplos usos. O feno da macega é incorporado nos canteiros de cultivo com o objetivo de aumentar a porosidade do solo, diminuindo o encharcamento dos canteiros durante o inverno, bem como para adubação.
Durante os meses de verão, a macega e o junco podem ser utilizados como cobertura vegetal durante o período de emergência das plântulas cultivadas (e.g. cenoura), bem como para evitar o contato direto de frutos com o solo (e.g. morango, melão e melancia). Nas propriedades rurais com criação de animais (gado, cavalos e porcos), a macega e o junco são utilizados como cama. Este feno enriquecido com fezes e urina é reaproveitado posteriormente como esterco para adubação da lavoura, durante o período de cultivo na primavera e verão. Além disso, ainda é possível encontrar pequenos galpões construídos de macega (Ilha dos Marinheiros), utilizados para armazenamento de produtos e equipamentos. Segundo os agricultores, em média são utilizados $1.580 \mathrm{~kg}$ PS.ha ${ }^{-1}$.ano ${ }^{-1}$ de macega, equivalente a $6,4 \%$ da produção anual média (produção estimada = 24.462 kg PS.ha ${ }^{-1}$; PEIXOTO; COSTA, 2004) para cama de animais/adubação e construção de galpões. A utilização de junco alcança $6.800 \mathrm{~kg}$ PS.ha ${ }^{-1}$.ano ${ }^{-1}$, removendo em torno de $20,5 \%$ da produção média anual (produção estimada = $33.098 \mathrm{~kg} \mathrm{PS} \mathrm{ha}{ }^{-1}$.ano ${ }^{-1}$; GAONA et al., 1996). 
Não ocorreram modificações nas formas de uso das marismas adjacentes às propriedades agrícolas nas últimas décadas; entretanto, foi verificada uma substancial diminuição na quantidade de vegetação utilizada. Todos os agricultores entrevistados afirmaram ter utilizado no passado plantas de marismas como insumo em suas propriedades; porém, atualmente apenas $11 \%$ dos agricultores usam o junco e $22 \%$ usam a macega. Vários fatores contribuíram para esta redução, destacando-se a diminuição da área cultivada em virtude da menor disponibilidade de mão de obra familiar, a utilização de adubação química (fertilizantes), a redução ou supressão da criação de animais - em parte associada ao aumento do abigeato - e a construção e/ou cobertura de galpões com outros materiais.

Tanto pecuaristas como agricultores relataram o emprego tradicional de macega e eventualmente de junco para cobertura de galpões e casas, atividade conhecida popularmente por quinchar (palavra de origem espanhola platense significando "fazer a cobertura ou quincha de"; FERREIRA, 2004). Segundo alguns entrevistados, utilizava-se entre 1.000 a 10.000 feixes de plantas para a cobertura de galpões e casas, apresentando uma durabilidade de 10 a 20 anos. Com a aquisição de materiais mais duradouros e menos suscetíveis aos incêndios, tais como telhas de barro e/ou de amianto, este uso diminuiu significativamente nos últimos 30 anos. A cobertura de casas com macega é relatada desde o início da colonização de Rio Grande, em 1740, como reportado por André Ribeiro Coutinho, que descreveu a substituição do uso na cobertura das casas do couro por palha (COUTINHO, 1936 apud QUEIROZ, 1987). Em 1780, Sebastião Francisco Bettamio relatou que a madeira e os capins usados para cobertura das casas pela Fazenda Real e moradores da Vila do Rio Grande eram obtidos na Ilha dos Marinheiros (FREITAS, 1980).

A expansão do junco sobre os campos e macega foi a principal mudança ambiental nos últimos 50 anos, apontada pelos pecuaristas e agricultores. A combinação dos relatos sugere que esta expansão foi primeiramente percebida na margem sudoeste do estuário (Justino e Ilha do Leonídeo, nos últimos 30-50 anos) e está avançando em direção norte (Arraial e Torotama, nos últimos 10-30 anos). O avanço do junco vem diminuindo substancialmente as áreas de pastagem para o gado, tradicionalmente sobre campos e macega, bem como áreas agrícolas não cultivadas, fazendo com que a maioria dos entrevistados tenha interesse e/ou já tenha efetuado ação direta de manejo (remoção) nas áreas invadidas através da aplicação de herbicidas, lavragem e fogo. O junco da marisma ( $\mathrm{J}$. kraussii) é uma planta sensível às altas salinidades durante a germinação e estabelecimento, apresentando uma condição ótima de crescimento em salinidades de até 15 (ZEDLER et al., 1990; GREENWOOD; MACFARLANE, 2006; NAIDOO; KIFT, 2006). Costa et al. (2003) relatam uma salinidade média decadal no final do século XX ao sul da Ilha dos Marinheiros de 9. A expansão do junco pode estar associada a uma possível diminuição da salinidade no estuário, causada pelo aumento de descarga de água doce na bacia norte da Lagoa dos Patos (MARENGO, 2006) e/ou pelo aumento no tempo de residência de água doce na região central do estuário, devido à construção de aterros (década de 1970) entre a Ilha do Leonídeo e Ilha dos Marinheiros. Möller e Fernandes (2010) constataram um aumento no nível de água de $2,5 \mathrm{~mm} . \mathrm{ano}^{-1}$ na desembocadura da Lagoa dos Patos que, aparentemente, está relacionado com o aumento na descarga de água doce dos principais tributários.

O uso e a existência da marisma na área urbana foram fortemente condicionados por fatores socioeconômicos e ambientais. A expansão urbana e aumento da demanda por moradia converteram as marismas, levando ao aterramento deste ecossistema no entorno da cidade de Rio Grande (MARANGONI; COSTA, 2009a). Processos erosivos naturais vêm contribuindo para a supressão das marismas, sendo esta, inclusive, a principal mudança ambiental relatada pelos entrevistados no meio urbano. Algumas áreas remanescentes de marismas na zona urbana são utilizadas como pastagem para cavalos (carroceiros).

A maioria dos entrevistados, independentemente do grupo analisado, acredita não existir relação entre as marismas e a fauna estuarina. Esta dissociação pode estar relacionada com a concepção de que os peixes e camarões vivem exclusivamente nas enseadas rasas (sacos), longe das margens. Por outro lado, quase todas as pessoas entrevistadas atribuíram um papel imprescindível das plantas de marisma como uma barreira natural de proteção contra a erosão das margens. Esta opinião provavelmente está atrelada à observação da maior agressividade do processo erosivo nas margens sem vegetação. De maneira geral, há um desconhecimento da legislação pertinente às marismas por praticamente todos os entrevistados, sendo eventualmente comentada a proibição de atear fogo nos ambientes naturais (p. ex., campo, marisma, mata). 


\section{Conclusões}

As atividades tradicionais de pecuária extensiva com baixa lotação e agricultura em pequenas propriedades têm permitido a manutenção dos principais processos ecológicos das marismas do estuário da Lagoa dos Patos ao longo do último século. Os resultados das entrevistas sugerem que estas atividades econômicas podem ter atingido um estado de "desenvolvimento viável", descrito por Weber (1996) como ocorrendo quando estratégias adaptativas das atividades antrópicas abrangem tanto as variabilidades no sistema natural quanto as variabilidades no sistema econômico. Todavia, deve ser ressaltado que qualquer mudança ambiental e/ou mudança na atividade econômica no entorno das marismas

\section{Referências}

ABREU, P. C.; COSTA, C. S. B.; BEMVENUTI, C.; ODEBRECHT, C.; GRANÉLI, W.; ANÉSIO, A. M. Eutrophication Processes and Trophic Interactions in a Shallow Estuary: Preliminary Results Based on Stable Isotope Analysis ( $813 \mathrm{C}$ and 815 N). Estuaries and Coasts, v. 29, n. 2, p. 277-285, 2006.

ADAM, P. Saltmarsh Ecology. New York: Cambridge University Press, 1990.

ALMEIDA, R. Consumo e eficiência alimentar de bovinos em crescimento. Piracicaba, Tese (Doutorado em Ciência Animal e Pastagens) - ESALQ/USP, 2005. Disponível em: $<$ http://www. teses.usp.br/teses/disponiveis/11/11139/tde-09112005-150314/ publico/ RodrigoAlmeida.pdf>. Acesso em: dez. 2007.

BARBOSA, F. A. Consumo de pastagens pelos bovinos. Disponível em: <http://www.agronomia.com.br/conteudo/ artigos/artigos_consumo_pastagens_bovinos.htm $>$. Acesso em: dez. 2007.

BERG, B. L. Snow Ball Sampling. In: KOTZ, S.; BALAKRISHNAN, N.; READ, C. B.; VIDAKOVIC, B. (Ed.). Encyclopedia of Statistical Sciences. 2. ed. New Jersey: John Willey \& Sons, Inc., 2006.

BRASIL. Lei n. 4.771, de 15 de setembro de 1965. Institui o novo Código Florestal. Brasília: DOU de 16/9/1965.

COIMBRA, F. L.; COSTA, C. S. B. Mapeamento digital dos macro-hábitats de dunas e marismas da costa do Rio Grande do Sul através de imagens de satélite e fotografias aéreas. In: ENCONTRO NACIONAL DE GERENCIAMENTO COSTEIRO, podem levar a outro tipo de interação, produzindo infinitas consequências.

A pecuária parece atuar nas marismas de maneira similar nas últimas décadas, contrastante com a agricultura - a qual vem continuamente diminuindo sua ação. Fatores socioeconômicos e ambientais são as principais responsáveis pela supressão das marismas nas áreas urbanas, praticamente extinguindo os usos das marismas pelos moradores urbanos.

O conhecimento empírico dos entrevistados aponta para uma importante mudança ambiental nas marismas, nos últimos 50 anos, que é a expansão do junco ( $J$. kraussii) sobre as áreas de campos e macega. Esta alteração da cobertura vegetal está provavelmente associada às mudanças no padrão hidrológico do estuário.

nov. 2006. Anais. São Vicente, 2006. Disponível em: <http:// www.costasul.furg.br/ global/articles/ Coimbra\&Costa2006. pdf>. Acesso em: out. 2009.

CORDOVA, F. J.; WALLACE, J. D.; PIEPER, R. D. Forage intake by grazing livestock: A review. Journal of Range Management, v. 31, n. 6, p. 430-438, 1978.

COSTA, C. S. B.; DAVY, A. J. Coastal saltmarsh communities of Latin America. In: SEELIGER, U. (Ed.). Coastal plant communities of Latin America. San Diego: Academic Press, Inc., 1992.

; IRIBARNE, O. O.; FARINA, J. M. Human impacts and threats to the conservation of South American salt marshes. In: SILLIMAN, B. R.; GROSHOLTZ, T.; BERTNESS, M. D. (Ed.). Salt Marshes under Global Siege. Berkeley: University of California Press, 2009.

; MARANGONI, J. C.; AZEVEDO, A. M. G. Plant zonation in irregularly flooded salt marshes: relative importance of stress tolerance and biological interactions. Journal of Ecology, v. 91, p. 951-965, 2003.

; SEELIGER, U.; OLIVEIRA, C. P. L.; MAZO, A. M. M. Distribuição, funções e valores das marismas e pradarias submersas no Estuário da Lagoa dos Patos (RS, Brasil). Atlântica, v. 19, p. 67-85, 1997.

CUNHA, S. R.; ASMUS, M.; COSTA, C. S. B. Production dynamics of Spartina alterniflora salt marshes in the estuary of Patos Lagoon (RS, Brazil): a simulation model approach. Braz. J. Aquat. Sci. Technol., v. 9, n. 2, p. 75-85, 2005. 
DIEGUES, A. C. Ecologia humana e planejamento costeiro. 2. ed. São Paulo: NUPAUB, 2001.

D'INCAO, F.; SILVA, K. G.; RUFFINO, M. L.; BRAGA, A. C. Hábito alimentar do caranguejo Chasmagnathus granulata Dana, 1851 na Barra do Rio Grande, RS (Decapoda, Grapsidae). Atlântica, v. 12, n. 2, p. 85-93, 1990.

FERREIRA, A. B. H. Novo Dicionário Aurélio da Língua Portuguesa. 3. ed. Curitiba: Positivo, 2004.

FREIRE, E. F. O. Do rural ao urbano: as relações sociais de produção e as formas de inserção econômica dos agricultores familiares da Ilha dos Marinheiros. Rio Grande - RS. Monografia (Curso de Graduação em Geografia) - FURG. Rio Grande, 2003.

FREITAS, D. O capitalismo pastoril. Escola Superior de Teologia São Lourenço de Brindes - UCS. 1980.

GAONA, C. A. P.; PEIXOTO, A. R.; COSTA, C. S. B. Produção primária de uma marisma raramente alagada dominada por Juncus effusus L., no extremo sul do Brasil. Atlântica, v. 18, p. 43-54, 1996.

GREENWOOD, M. E.; MACFARLANE, G. R. Effects of salinity and temperature on the germination of Phragmites australis, Juncus kraussii, and Juncus acutus: implications for estuarine restoration initiatives. Wetlands, v. 26, n. 3, p. 854-861, 2006.

IBGE. Censo Agropecuário 1996. Disponível em: <http:// www.ibge.gov.br/home/ estatistica/economia/agropecuaria/ censoagro/1995_1996/default.shtm>. Acesso em: mar. 2008.

. Censo Agropecuário 2006 - Resultados Preliminares. Disponível em: <http://www.ibge.gov.br/home/estatistica/ economia/agropecuaria/censoagro/2006/default.shtm $>$. Acesso em: jun. 2009.

Contagem da População 2007. Disponível em: $<$ http:// www.ibge.gov.br/home/ estatistica/populacao/contagem2007/ default.shtm>. Acesso em: jun. 2009.

MANZONI, J. D. Estratégias para o ecodesenvolvimento da agricultura na Ilha dos Marinheiros-Rio Grande-RS: uma abordagem sob a ótica de Ignacy Sachs. Dissertação (Mestrado em Educação Ambiental) - FURG. Rio Grande, 2007.

MARANGONI, J. C.; COSTA, C. S. B. Natural and anthropogenic effects on salt marsh over five decades in the Patos Lagoon (southern Brazil). Brazilian Journal of Oceanography, v. 57, n. 4. p. 345-350, 2009a.

Diagnóstico ambiental das marismas no estuário da Lagoa dos Patos - RS. Atlântica, v. 31, n.1. 2009 b. No prelo.
MARENGO, J. A. Mudanças climáticas globais e seus efeitos sobre a biodiversidade: caracterização do clima atual e definição das alterações climáticas para o território brasileiro ao longo do século XXI. Biodiversidade 26. Brasília: MMA, 2006. Disponível em: $<$ http://www.mma.gov.br/estruturas/imprensa/_arquivos/livro\%20completo.pdf $>$. Acesso em: out. 2009.

MÖLLER, O.; FERNANDES, E. Hidrologia e hidrodinâmica. In: SEELIGER, U; ODEBRECHT, C. (Ed.). O estuário da Lagoa dos Patos: um século de transformações. Rio Grande: Universidade Federal do Rio Grande, 2010.

NAIDOO, G.; KIFT, J. Responses of the saltmarsh rush Juncus kraussii to salinity and waterlogging. Aquatic Botany, v. 84, p. 217-225, 2006.

NOGUEIRA, R. X. S.; COSTA, C. S. B. Mapeamento das marismas do estuário da Lagoa dos Patos (RS) utilizando fotografias aéreas digitais $35 \mathrm{~mm}$ no modo infravermelho. In: CONGRESSO DA ASSOCIAÇÃO BRASILEIRA DE ESTUDOS DO QUATERNÁRIO - ABEQUA, 2., out. 2003. Resumos expandidos. Recife, 2003. Disponível em: <http:// www.peld.furg.br/grp/ccosta/Anais/Nogueira\&Costa2003b. PDF>. Acesso em: jan. 2007.

PEIXOTO, A. R. Análise simultânea da produção primária das comunidades de macrófitas emergentes dominantes das marismas do estuário da Lagoa dos Patos (RS) - Brasil. Dissertação (Mestrado em Ecologia) - UFRGS. Porto Alegre, 1997.

PEIXOTO, A. R.; COSTA, C. S. B. Produção primária líquida aérea de Spartina densiflora Brong. (Poacea) no estuário da Lagoa dos Patos, Rio Grande do Sul, Brasil. Iheríngia, Ser. Bot., v. 59, n.1, p. 27-34, 2004.

QUEIROZ, M. L. B. A vila do Rio Grande de São Pedro 17371822. Rio Grande: FURG. 1987.

RIO GRANDE. Lei Municipal n. 4.116, de 03 de novembro de 1986. Plano Diretor de Desenvolvimento Integrado. Rio Grande.

SEELIGER, U.; COSTA, C. S. B. Impactos Naturais e Humanos. In: SEELIGER, U.; ODEBRECHT, C.; CASTELLO, J. P. (Ed.). Os ecossistemas costeiro e marinho do extremo sul do Brasil. Rio Grande: Editora Ecoscientia, 1998.

VERNEQUE, R. S. Estimativas de consumo do capim-elefante (Pennisetum purpureum Schum), fornecido picado para vacas lactantes utilizando a técnica do óxido crômico. Disponível em: $<$ http://br.monografias.com/trabalhos901/consumo-capim-elefante/ consumo-capim-elefante.shtml>. Acesso em: dez. 2007.

VIEIRA, E. F.; RANGEL, S. S. Geografia econômica do Rio Grande do Sul. Porto Alegre: Sagra-Dc Luzzatto. 1993. 
WEBER, J. 1996. Gestão de recursos renováveis: fundamentos teóricos de um programa de pesquisas. In: VIEIRA, P. F.; WEBER, J. (Org.). Gestão de recursos naturais renováveis e desenvolvimento. 3. ed. São Paulo: Cortez Editora, 1996.
ZEDLER, J. B.; PALING, E.; McCOMB, A. Differential responses to salinity help explain the replacement of native Juncus kraussii by Typha orientalis in Western Australian salt marshes. Australian Journal of Ecology, v. 15, p. 57-72, 1990.

Recebido em dezembro de 2009. Aceito em julho de 2010. Publicado em dezembro de 2010. 